\title{
Crianças com câncer e o atendimento educacional nos ambientes hospitalar e escolar
}

Carmem Lúcia Artioli Rolim

Universidade Federal do Tocantins

Maria Cecília Rafael de Góes

Universidade Metodista de Piracicaba

\section{Resumo}

Este trabalho aborda o atendimento educacional oferecido a crianças com câncer, que precisam afastar-se da escola por períodos longos ou recorrentes em razão do tratamento. 0 sistema escolar não tem respondido às necessidades desses alunos e são ainda escassas as iniciativas de classe hospitalar e atendimento domiciliar. Para discutir o problema, apresentamos uma pesquisa referenciada na abordagem histórico-cultural e realizada no âmbito de um programa educacional num hospital de câncer infantil. 0 objetivo foi analisar a significação que as crianças atribuíam ao aprender e sua receptividade a experiências de aprendizagem. Durante o programa, elas mostravam um claro desejo de participar das atividades, mas manifestavam uma grande insatisfação com o retorno à escola. Além de se confrontarem com preconceitos pela doença, não recebiam apoio para alcançar o ritmo da classe e geralmente cumpriam as lições mediante meras cópias. As avaliações eram feitas sem exigências e a promoção, facilitada. Assim, o direito a aprender era tornado um direito a não aprender. Essa mescla de despreparo e condescendência da escola leva ao desperdício do potencial e da vitalidade das crianças e produz uma dor adicional, um senso de inferioridade. Há divergências nessa área quanto à atenção a ser dada às atividades instrucionais, já que é essencial minimizar o sofrimento da criança. Os presentes dados indicam que o conhecimento escolar não deve ser secundarizado, pois ele preserva vínculos com esferas da cultura e, sobretudo, constitui uma fonte de vontade de viver pelo seu valor de futuro projetado.

\section{Palavras-chave}

Crianças com câncer - Necessidades educacionais - Educação e saúde.
Correspondência:

Maria Cecilia Rafael de Góes

Rua Fernando F. da Costa, 1419 apto. 102

13416-253 - Piracicaba - SP

e-mail: mcrgoes@unimep.br 


\section{Children with cancer and the educational service in hospitals and schools}

Carmem Lúcia Artioli Rolim

Universidade Federal do Tocantins

Maria Cecilia Rafael de Góes

Universidade Metodista de Piracicaba

\begin{abstract}
This work deals with the issue of the educational service offered to children with cancer that need to stay away from school for prolonged or recurrent periods of time as a consequence of their treatments. The school system has not been able to respond adequately to the needs of these students, and the initiatives of hospital classes and home schooling are still rare. To put this theme in discussion, we present a study based on a historical-cultural approach carried out within an educational program at a hospital for children with cancer. The objective here was to analyze the meaning attributed by children to the act of learning, and their receptiveness to learning experiences. During the program they showed a clear desire to take part in the activities, but demonstrated strong dissatisfaction with their return to school. In addition to facing prejudice against their health condition, they received no support to help them to catch up with their class, and usually ended up completing their school tasks by mere copying. Assessments were non-demanding, and promotion facilitated. Thus, their right to learn was turned into a right not to learn. The combination of lack of preparation with condescendence from the school leads to the potential and vitality of these children being put to waste, producing additional pain and a sense of inferiority. There are controversies around the issue of how much attention should be given to instructional activities, since it is essential to minimize the child's suffering. The results presented here suggest that the school knowledge should not be placed in a secondary position because it preserves ties with the spheres of culture and, above all, it constitutes a source of will to live in view of its value as a projected future.
\end{abstract}

\section{Keywords}

Children with cancer - Educational needs - Education and health.
Contact:

Maria Cecilia Rafael de Góes

Rua Fernando F. da Costa, 1419 apto. 102

13416-253 - Piracicaba - SP

e-mail: mcrgoes@unimep.br 
0 atendimento educacional para crianças hospitalizadas vem ocorrendo timidamente no Brasil desde 1950, ano de criação da primeira classe hospitalar no Hospital Municipal Jesus, no Rio de Janeiro. A segunda foi inaugurada em 1953, na Santa Casa de Misericórdia, em São Paulo. A implantação dessa modalidade de educação ganhou incentivo apenas quatro décadas depois, quando os órgãos públicos começaram a inserir as classes hospitalares em suas políticas de educação.

Programas de educação em hospitais, antes dependentes de iniciativas isoladas, ganham impulso a partir de sua oficialização pela legislação brasileira. Em 1994, a Secretaria de Educação Especial do Ministério da Educação - SEESP/MEC - regulamentou o atendimento de crianças impedidas de frequentar a escola por motivo de saúde, apresentando diretrizes para subsidiar a organização de atividades pedagógicas em classe hospitalar e no ambiente domiciliar e para fundamentar a ação do professor (Brasil, 1994). Esse compromisso foi também previsto nas Diretrizes Nacionais para a Educação Especial na Educação Básica (Brasil, 2001) e em documento do SEESP/MEC que estabelecia estratégias e orientações sobre a classe hospitalar e o atendimento pedagógico domiciliar (Brasil, 2002).

Conforme levantamento feito por Fonseca (1999), no final da década de 1990, existiam no Brasil 39 classes com atendimento escolar para seus pacientes, alocadas em 30 hospitais: 11 deles infantis. É possível que os números fossem maiores, pois as classes hospitalares nem sempre têm essa denominação e estão ligadas às mais diversas iniciativas, entre as quais estão os projetos experimentais de Secretarias da Educação, de Secretarias da Saúde, de universidades e de organizações não governamentais. Os dados levantados pelo autor mostram que, na maioria das vezes, as classes não tinham um professor responsável e eram desenvolvidas por bolsistas, estagiários e voluntários. Quanto ao espaço físico, apenas 46\% delas funcionavam em salas destinadas à realização das atividades (23\% em ambiente exclusivo e $23 \%$ em ambiente adaptado). As demais utilizavam corredores e enfermarias.

0 oferecimento de ações educacionais para a criança enferma é um grande avanço, visto que, a partir da relação entre família, equipe médica e equipe educacional, é propiciada a continuidade de um projeto de vida e a busca de realização. Por outro lado, trata-se de um desafio que envolve com igual intensidade esforços de profissionais da saúde e da educação. Embora instâncias oficiais e organizações civis reconheçam esse direito, ainda se faz necessário ativar outros mecanismos sociais para que seja concretizado. Como diz Matos (2006):

Há muito que caminhar no vasto pluralismo multiforme de ações educativas, que hoje estão se desenvolvendo em tantas e tão variadas dimensões do trabalho social. Uma dessas dimensões se faz existir no hospital, um contexto social que até há pouco tempo estava totalmente esquecido. (p. 43-44)

\section{O tratamento hospitalar e a condição de vida do paciente com câncer}

0 câncer despontou como uma das maiores causas de mortalidade já na década de 1920, segundo o Instituto Nacional do Câncer (INCA, 2000). Com o tempo, o avanço da tecnologia e os investimentos na saúde pública, a doença, que tinha o estigma de patologia incurável, passa a ser considerada como recuperável, embora continuando com números alarmantes. Em 2007, foi a terceira causa mortis de crianças entre 1 e 14 anos de idade.

0 adoecimento infantil acomete uma fase crucial do desenvolvimento humano e, nas palavras de Nigro (2004), em doenças como o câncer, constitui uma violência impositiva em razão da necessidade de tratamento e internação. Isso é algo que não se discute, acata-se. 0 estar doente exige um esforço físico e psicológico para a preservação da vida, 
além de um esforço social redobrado para enfrentar os tratamentos agressivos, que podem provocar mutilações, e a percepção de um anúncio da morte. 0 afastamento de várias esferas do meio social torna-se inevitável, muitas perdas são percebidas e o receio da morte instala-se. A criança necessita de cuidados especiais em espaços que são distintos daqueles envolvidos na maioria das rotinas de sua vida. Ademais, no espaço hospitalar, ela entra em grande sofrimento à medida que é despojada de suas roupas, de seus pertences e do convívio com a maioria de seus familiares. No entanto, mesmo diante dessa fragmentação da vida, ela continua a ter fantasias, emoções e sentimentos, o que demanda uma visão de tratamento que contemple as especificidades da infância e uma compreensão integral do desenvolvimento do sujeito.

Esse processo de sofrimento é uma jornada que tem início com o diagnóstico da doença. A criança, antes no auge de seu dinamismo, entra num processo de internações sucessivas. As restrições trazidas pela doença e pelo tratamento causam debilidades e afetam a atividade física, o que muitas vezes agrava a angústia causada pela enfermidade, podendo levar a um estado estressante, com consequências para o quadro clínico. Entretanto, a atenuação dessas consequências de ordem emocional encontra algumas barreiras, entre as quais vale destacar a frieza, ainda existente, dos profissionais que lidam com a vida e a morte.

Quanto a essa realidade, Foucault (2001) salienta a maneira distante com que médicos tratam pacientes, camuflando esse distanciamento em normas centradas na doença, e assim "paradoxalmente, o paciente é apenas um fato exterior àquilo que sofre; [...] o sucesso da cura depende de um exato conhecimento da doença” (p. 7). Da perspectiva médica, o paciente é reconhecido, mas apenas como espaço de desenvolvimento da doença.

A doença é, assim, tomada em um duplo sistema de observação: um olhar que a confunde e a dissolve no conjunto das misérias sociais a suprimir; e um olhar que a isola para melhor circunscrevê-la em sua verdade de natureza. (p. 46)

No caso do câncer, a enfermidade é particularmente estigmatizada pela sociedade. Apesar dos avanços tecnológicos e do aumento das chances de cura, as dores físicas causadas pela doença e pelo tratamento só são equiparadas às dores causadas pela segregação social que os estigmas produzem. Sontag (1984) salienta que os discursos marcados pelo estigma permeiam o cotidiano da pessoa com câncer de vários ângulos. A par das atribuições de causas (punitivas, sentimentais, sobrenaturais), há ainda uma construção social que se expressa por muitas metáforas, relacionando a doença a uma aniquilação individual e o tratamento a uma luta militar que envolve explorações, invasões, bombardeios, infiltrações. Uma guerra química em que o paciente sempre perde e o objetivo é perder o menos possível. Nessa mesma guerra em que existe a esperança de vencer, a derrota está igualmente presente. É a necessidade de exames "exploratórios" que vão mapear as células "invasoras" a serem extirpadas, "destruindo" o câncer que "devora".

Essas considerações são fundamentais para compreender um pouco a situação de vida em que se encontram as crianças focalizadas neste estudo. Elas apresentam trajetórias diferentes em termos do processo de diagnóstico e enfrentamento da doença, mas em vários pontos suas histórias se identificam, sobretudo pelos sentimentos de intensa tristeza e pelo desejo de "retomar a vida" em meio aos sofrimentos físicos e aos preconceitos que as atingem.

Mesmo ao receberem alta, sua alegria não parece ter o mesmo significado da recuperação de outras doenças, pois o breve alívio da melhora logo se entrelaça com o temor do retorno à condição que as afeta e da qual demonstram ter consciência, embora de diferentes maneiras, dependendo da idade ou etapa de desenvolvimento. 


\section{O desenvolvimento do psiquismo e compromentimentos da saúde na infância}

Recorrendo ao pensamento de Vygotsky (1995; 1997) e Leontiev (1983; 1988), procuramos incorporar proposições gerais da abordagem histórico-cultural sobre os processos humanos, em especial aquelas mais vinculadas ao desenvolvimento da criança, que podem ser estendidas para interpretar condições da infância comprometida por problemas de saúde.

Dessa perspectiva teórica, o desenvolvimento é um processo não linear, marcado por rupturas, continuidades e superações, em transformações que resultam das vivências do sujeito no grupo social (Vygotsky, 1995). 0 processo de individuação, de tornar-se indivíduo, tem gênese nas relações sociais desde o nascimento e acontece à medida que a criança incorpora a cultura (entendida amplamente como atividade social humana e produto da vida social). A formação da personalidade caminha, então, da instância social para o individual, num movimento que implica a internalização ou conversão para si dos significados das interações do sujeito com outros. A síntese dessas ideias está no que o autor denominou de lei de dupla formação, segundo a qual as funções psíquicas aparecem inicialmente no plano social ou intersubjetivo e são internalizadas ou convertidas, formando o plano individual ou intrassubjetivo.

A interação do ser humano com o mundo não é, portanto, uma relação direta, mas uma relação mediada pelas outras pessoas e pelas produções humanas, que depende das atividades concretas em que ele se envolve e não se restringem aos encontros face a face.

Sob essa matriz teórica, outro conjunto de proposições que tem relevância para o presente trabalho refere-se à relação entre os conceitos de desenvolvimento e de atividade em Leontiev $(1983$; 1988). Para o autor, a atividade é prática social que resulta de uma necessidade coletiva; é uma construção cultural que orienta o indivíduo na relação com o meio. Portanto, não pode ser entendida como uma ação isolada ou um conjunto de ações fragmentadas. A atividade individual está estreitamente ligada àquela configurada pelo grupo social, situado num determinado tempo e espaço.

Diferentes tipos de atividade coexistem, porém ocupam posições diferenciadas ao longo do desenvolvimento ontogenético, podendo ser atividade principal em certo estágio e secundária em outro. Num dado estágio, a atividade principal é assim denominada por desempenhar papel essencial na vida do sujeito, enquanto outras são secundárias por exercerem papel subsidiário. Isso significa que as atividades têm caráter diferenciado, com suas motivações específicas, conforme acontecem as mudanças de personalidade.

Delineando um panorama geral, Leontiev (1988) salienta que a atividade principal no período pré-escolar é a brincadeira. Já no período escolar, corresponde ao estudo, às experiências instrucionais. Na vida adulta, consiste no trabalho. Portanto, a atividade principal não é definitiva, ela passa por transições que correspondem à necessidade da pessoa e à "agenda” estabelecida pelo grupo social. Precisamente por isso não podemos caracterizar de maneira uniforme (independente da cultura) a noção de atividade principal. Tudo depende das condições reais de vida e é preciso lembrar que a criança pertence a um grupo social e a uma determinada época. Há diferentes infâncias, não uma infância abstrata. Numa sociedade, temos crianças com e sem acesso à atividade instrucional; outras entram prematuramente na atividade trabalho e assim por diante. No entanto, em princípio, quando as condições são dadas, a chegada da fase escolar faz com que a criança e sua família vivenciem um tempo em que as relações de vida se reorganizam e a escola passa a ocupar um lugar central, e as ações nela concretizadas estão dentro de uma ideia social de atividade.

Visto que para o presente trabalho interessa considerar a infância afetada por graves problemas de saúde, retomamos discussões de Vygotsky (1997) que dizem respeito a crianças cujo desenvolvimento está comprometido por 
fatores orgânicos. Esse tema foi discutido intensamente pelo autor no âmbito das condições de deficiência (sensorial ou mental) e de problemas de conduta. Entendemos que suas interpretações são muito pertinentes também aos casos de crianças com doenças como o câncer, tanto pela existência de uma grave e limitante enfermidade como pela suscitação de preconceitos no grupo social e a consequente restrição de experiências favoráveis ao desenvolvimento.

Segundo esse teórico, tendo em vista que desde o nascimento toda criança está em um mundo social e historicamente organizado, os princípios gerais dos processos humanos são os mesmos para indivíduos em condição normal e para aqueles que apresentam especificidades orgânicas de desenvolvimento. Entretanto, nesse segundo caso, há peculiaridades na formação sociopsicológica às quais se acrescentam as consequências sociais do fator orgânico. As necessidades advindas de condições peculiares existem e não podem ser ignoradas, é claro. Contudo, a ação social e particularmente a educação deve ser direcionada para as possibilidades de desenvolvimento da criança, para experiências de aprendizagem que elevem seus modos de funcionamento psíquico e favoreçam sua inserção nas diferentes esferas da vida cultural.

Criticando a centração das ações educativas no quadro orgânico, Vygotsky (1997) diz que devemos reconhecer a enfermidade, mas, sobretudo, observar a pessoa que apresenta essa enfermidade. Além disso, é fundamental considerar as possibilidades que a criança apresenta, pois o comprometimento orgânico não resulta num desenvolvimento menor, a depender do que a vida social propicia a ela, especialmente na experiência escolar. Se a educação assume expectativas limitadas e subestima a criança, ocorre um conformismo que conduz a baixas exigências e a uma pedagogia que possibilita menos e exclui mais. Ao invés de oferecer elementos propulsores de desenvolvimento, a postura de passividade educativa faz surgir o insucesso, a incapacidade e a desvalorização social. Ao contrário, a educação deve orientar esforços para o núcleo vital saudável da criança.

No caso de crianças com câncer, sabemos que a doença participa da constituição de sua subjetividade, marca profundamente sua história e os modos de relação social em que elas se envolvem. Numa condição que limita a vida e põe no horizonte o risco de morte, suas vivências são seriamente afetadas pela limitação de acesso a espaços de convivência e atividade e pela imagem que passa a ser-lhe atribuída, carregada de estigma. Por outro lado, conforme a perspectiva histórico-cultural, podemos dizer que as expectativas de seu desenvolvimento não devem ser rebaixadas e que o oferecimento de experiências de aprendizagem fortalece seu núcleo vital saudável.

Com base nesse aporte teórico, em especial no que concerne à educação como fonte de desenvolvimento e à noção de atividade como prática social, realizamos um estudo no contexto de um programa educacional em espaço hospitalar com o objetivo de analisar os modos pelos quais essas crianças significam o aprender e respondem a experiências de aprendizagem.

\section{Apontamentos sobre a significação do aprender para crianças com câncer}

\section{O contexto da pesquisa}

0 programa educacional em que o estudo ocorreu foi realizado num hospital de câncer infantil de uma cidade do interior do estado de São Paulo. Sua implementação, em 2004, resultou de um convênio entre o hospital e uma universidade local sob a coordenação da primeira autora. Por várias circunstâncias, não foi possível contar com o envolvimento da secretaria de educação municipal para configurar a proposta como classe hospitalar.

0 hospital em que o programa está sendo realizado tem a finalidade de prestar assistência integral a crianças e adolescentes (0-18 anos) portadores de neoplasia maligna, e rea- 
liza em média 120 atendimentos mensais (diagnóstico, tratamento, acompanhamento e novas consultas). Trata-se de uma entidade beneficente, fundada em 1983, que oferece assistência médica e hospitalar, bem como assistência social extensiva aos familiares. Atende principalmente pacientes que são de famílias muito pobres ou possuem planos de saúde que não cobrem o tratamento de câncer. Financeiramente ele é mantido pelo SUS e pela comunidade local por meio do apoio de diferentes instituições, empresas e indivíduos. Seu objetivo é o atendimento ao paciente com câncer, a fim de recuperá-lo dentro de suas possibilidades físicas. Além disso, desenvolve pesquisas nessa área.

Como vários dos pacientes não têm residência próxima, a instituição provê estadia numa ala de apoio com quartos, banheiros privativos e uma cozinha comunitária. Esse espaço é destinado ao familiar do paciente, na fase de internação, e a ambos, em fases de vindas ao hospital para consultas e acompanhamento.

Para o programa educacional, são disponibilizados dois microcomputadores (doados pela universidade) e materiais diversos para desenho, escrita e leitura. As sessões acontecem uma vez por semana após a primeira rotina de atendimento (coleta de exames e café da manhã) e antes do almoço, isto é, no periodo das 9 às 11 horas.

As atividades começaram com caráter recreativo-educacional, sem concentração em atividades tipicamente escolares, em parte porque a proposta não tinha se constituído como classe hospitalar e deixava a possibilidade de um período de implementação mais flexível. Contudo, no desdobramento, mesmo mantendo uma atenção ao propósito recreacional, passou a ter um caráter educacional-escolar para atender aos constantes pedidos de "lição" que as crianças faziam.

Os registros das sessões, anotados em diário de campo, mostraram uma nítida disposição das crianças para aprender, para participar das atividades oferecidas. Ao mesmo tempo, elas faziam constantes referências à escola, seja pela busca de uma experiência substitutiva (quando estavam afastadas) seja pela frustração que a volta às aulas criava. É importante lembrar que o afastamento da escola geralmente não se restringe a um período único e pode acontecer de forma recorrente pela necessidade de cuidados médicos ou de nova internação, no acompanhamento ou em casos de recidiva.

Diante dessas indicações, as análises incluíram os importantes efeitos que as experiências no espaço escolar tinham sobre elas. No presente relato, focalizamos esse ângulo dos achados, sem a pretensão de uma exposição minuciosa, e tecemos alguns comentários sobre o problema.

Pacientes com diferentes idades podem participar das sessões. Contudo, para a finalidade específica desta pesquisa, elegemos os registros relativos à faixa etária de 6 a 12 anos e focalizamos um período de dois anos de sessões (do final de 2005 ao início de 2007), abrangendo 15 sujeitos. 0 recorte etário se justifica pelo interesse nas dificuldades enfrentadas por crianças que estão no ensino fundamental e pelo fato de que, durante o período, era muito pequena a demanda de pacientes acima de 12 anos.

Os sujeitos, assim como os demais pacientes, frequentavam escolas públicas de diferentes cidades da região. De acordo com o relato das crianças e informações da mãe ou responsável, em nenhuma das escolas havia qualquer tipo de proposta de adaptação para enfrentar as dificuldades geradas pelos afastamentos e irregularidade da frequência desses alunos. Em relação ao desempenho acadêmico nos períodos em que iam à escola, as crianças diziam estar defasadas em termos de aprendizagem dos conteúdos em estudo e, em vários casos, defasadas até em termos da seriação no ensino fundamental.

Quanto ao delineamento metodológico, esta pesquisa configura-se como estudo de caso, uma modalidade de investigação que implica o esforço de inter-relacionar dados de um contexto singular, considerando as expe- 
riências dos sujeitos por envolver processos da vida social. Como indicam lüdke e André (1986) e Minayo (1994), nesse tipo de estudo e em outras variantes da pesquisa qualitativa, a investigação orienta-se essencialmente para processos e significados, atribuindo grande importância aos pontos de vista das pessoas estudadas. Ademais, nela a dimensão da intersubjetividade do pesquisador e do pesquisado é explicitamente assumida.

A base de dados foi composta por registros em diário de campo das observações durante as atividades. De forma complementar, também foram coletadas cópias de produções das crianças: textos, desenhos, exercícios manuscritos e materiais impressos de atividades no computador. As anotações de campo eram feitas pela coordenadora durante e ao final das atividades. Estagiários ou voluntários, quando disponíveis, auxiliavam nessa tarefa. Embora o uso de video-gravação tenha sido cogitado, esta não era uma alternativa apropriada, pois seria um recurso invasivo para crianças que enfrentam sérios problemas de autoimagem em razão das marcas visíveis dos efeitos da doença e do tratamento.

Sempre que possivel, conforme o detalhamento dos registros, os segmentos interativos foram examinados sob diretrizes da análise microgenética, caracterizada por Góes (2000) como uma forma de construção de dados que requer a atenção a detalhes das relações intersubjetivas e a condições sociais da situação, resultando num relato minucioso dos acontecimentos com ênfase nos processos dialógicos.

As análises consistiram de sucessivos exames das situações registradas, para chegar a uma organização por unidades temáticas pertinentes ao tema focal - a significação do aprender manifestada pelas crianças. 0 conjunto de achados abrange naturalmente questões relativas ao próprio espaço do programa, mas para o presente relato, destacamos apenas as indicações sobre a significação da experiência de aprendizagem no espaço da escola, revelada pelos dizeres das crianças durante as sessões.

\section{As crianças e sua experiência escolar}

As crianças chegam para as sessões suplantando dores causadas pela doença, pelas intervenções médicas e pelas diferentes formas de tratamento. Vêm com soro, ataduras, fraldas e, por vezes, carregadas ou em cadeiras de rodas. Querem participar sempre que possível. Suas falas indicam que essa disposição advém de uma mescla de motivações, pois elas encontram nas atividades um incentivo para realizar algo saudável, para encontrar forças diante do sofrimento ou mesmo para afastar-se dos fatos dolorosos que vivenciam. Existe um desejo claro de busca pela continuidade de aprendizagem que se relaciona com a perspectiva de futuro. Para elas, esse ambiente tem um propósito educacional e propicia certa liberdade de escolha das atividades, o que contrasta com a condição de paciente, em que são inevitavelmente tratadas sem opinar, envolvidas pela fria rotina hospitalar.

Assim, durante o período estudado, elas mostravam uma nítida receptividade para aprender. Ao mesmo tempo, faziam constantes referências à escola, seja pela busca de uma experiência substitutiva (quando estavam afastadas), seja pela frustração que a volta às aulas criava.

Os dados indicam que as crianças recém-afastadas da escola manifestam tristeza por perder essa parte rotineira de seu cotidiano. A atividade escolar não fica limitada apenas a uma lembrança, mas representa uma ponte para a vida, uma instância de ultrapassagem das paredes erguidas pela doença.

Já para aquelas que estão retornando à escola, o receio e a insegurança tornam-se fortemente presentes. Elas dizem que na sala de aula não acompanham os conteúdos, copiam muito (do caderno de colegas, do livro, da lousa) e há momentos em que ficam sem tarefa enquanto a classe trabalha. Quando relatam esses problemas, acrescentam comentários como "não sei nada, os outros sabem"; "não entendo nada”; "os outros gozam de mim"; "não sei escrever de mão, minha professora não ensina, quero muito aprender"; "não sei ler". 
O diagnóstico e o tratamento modificam antes de tudo a posição social da criança e todos seus vínculos com as pessoas em todos os momentos. A condição física provoca sofrimento, que é intensificado pela diferença que ela instaura nas relações sociais. A expectativa dos participantes do programa era superar as dificuldades vividas na sala de aula, e muitas das situações registradas deixam claro que a escola não as acolhe efetivamente como alunos que podem e devem aprender.

Constatamos que o significado do "pedir lição" difere conforme a fase: de tratamento, quando a criança permanece afastada da escola, e de acompanhamento ambulatorial, quando o afastamento é parcial. Na primeira circunstância, há indícios de sentimentos de saudade, sendo que, nas sessões do programa, a criança pode reconquistar um espaço roubado com a experiência de compartilhar atividades e fazer lição. Na segunda, as manifestações sobre o ambiente escolar são carregadas de emoção pelo problema que a criança enfrenta diante das exigências do mundo no qual tenta reintegrar-se, quando ela se defronta com dificuldades de desempenho escolar e preconceitos. Nesse momento, o fazer lição é buscado para compensar ou substituir a experiência na escola. No desdobramento do programa, alguns participantes passaram inclusive a vir para as sessões mesmo quando não tinham compromisso agendado no hospital.

Expomos a seguir algumas situações envolvendo crianças ${ }^{1}$ que estavam em fase de acompanhamento e tinham retornado à escola. Seus dizeres mostram como elas percebem e se ressentem da falta de acolhimento no ambiente escolar em termos do ensino oferecido e da qualidade da convivência.

\section{Situação 1}

Contexto: Leila (12 anos), Cacá (10 anos), Vânia (6 anos) e Marta ( 8 anos) estavam realizando atividades no computador. Então, Marta dirigiu-se a Carmem e disse que queria fazer outra coisa.
Marta: Oi, tia, vamos fazer lição?

Carmem: Que lição você quer?

Marta: Quero escrever... Pintar no papel.

Carmem: Bom eu não trouxe nada, mas posso passar contas, problemas e, da próxima vez, trago. Que tal? (Paula referia-se a não ter preparado previamente atividades para a menina.)

Marta: Manda.

Carmem: Que série você está?

Marta: Eu passei para quinta, mas frequentei mesmo até a terceira.

Carmem: Bom, vamos ver então... Você sabe adição e subtração?

Marta: Sei sim.

Carmem: Multiplicação?

Marta: Se for de vezes, sei sim.

Carmem: E divisão?

Marta: Essa não é tão fácil. Mas eu gosto de continhas. Problemas... Não!

Carmem: Então vamos ver se acerta essa?

Carmem propõe alguns exercícios e a menina vai tentando fazer.

Depois de algum tempo, Cacá, que está ao lado, pede se tem mais "continha". Carmem pergunta se ele acha difíceis as contas de Marta. Ele sorri e diz que gostaria de tentar. Carmem atende a seu pedido.

As manifestações de Marta e Cacá ilustram as constantes solicitações das crianças para fazer "lição, contas, exercícios". Essa expectativa das crianças, na maioria das vezes, parecia decorrer da necessidade de ajuda para a aprendizagem na escola, como podemos notar na fala de Letícia.

\section{Situação 2}

Contexto: Letícia (8 anos) já tinha terminado o tratamento e retornado à escola. Estava em fase de acompanhamento médico e vinha ao hospital para visitas agendadas. $\mathrm{Na}$ primeira vez que veio à sala, falou com Carmem, que estava coordenando a sessão

1. Os nomes das crianças são fictícios. 
no espaço dos computadores.

Letícia: Oi. Você é a professora?

Carmem: Sou sim. Qual o seu nome?

Letícia: Letícia.

Carmem: Olá, Letícia. Você vai entrar na

fila para mexer no computador?

Letícia: Quero brincar no computador, mas queria que você me ajudasse na escola.

Carmem: Está tendo problemas na escola?

Letícia: É, não sei escrever de mão, minha professora não ensina. Quero muito aprender.

Carmem: Qual sua série?

Letícia: Estou na segunda.

Carmem passa alguns exercícios de escrita e Letícia os realiza, registrando apenas as consoantes, sempre em letra de forma.

Percebendo que no retorno não estava acompanhando a classe, Letícia tentava adaptar-se, aprendendo a grafia manuscrita, que talvez nem fosse o mais importante nesse momento de aprendizado, porém já é utilizada pelos alunos da classe. Entretanto, esse era apenas um exemplo de que a escola não estimulava nem exigia dessa criança os deveres que eram atribuídos aos demais colegas, conforme ela diz numa sessão posterior.

\section{Situação 3}

Contexto: Nessa sessão, Carmem corrigia com Letícia a lição de casa (dada pela escola). A assistente social estava presente.

Assist. Social: Como você está indo na escola?

Letícia: Ah! Estou mais esperta. Copio rápido. To contente.

Carmem continua fazendo as correções com Letícia.

Carmem: Com quem você veio hoje?

Letícia: É minha vizinha. Minha mãe não pode vir, tem nenê novo. Mas eu venho bem, gosto da aula [do programa].

Carmem: Mas você está faltando na escola, lá também tem aula.

Letícia: É diferente.
Carmem: 0 que é diferente?

Letícia: Aqui eu aprendo. Lá eu copio bastante, mas não entendo nada. Agora to começando a entender um pouco.

As crianças buscam o estado saudável que perderam e essa preocupação as acompanha mesmo após o tratamento. 0 retorno à escola faz parte dessa busca. Entretanto, com a expectativa de dar conta dos conteúdos e das tarefas, aliada a intensos sentimentos advindos da doença, a experiência torna-se uma fonte de frustração. Letícia tem consciência de que fazer meras cópias não é aprender. A escola subestima sua capacidade, não a encoraja nem exige tarefas que são dadas aos demais colegas. Na sala de aula, os conteúdos são ensinados de maneira uniforme e as necessidades singulares ficam sem atenção. A criança doente, que está fragilizada e perdeu tantas aulas, tem de se adequar ao andamento da maioria com pouca ou nenhuma atenção pedagógica adicional. 0 tempo de afastamento é algo que ficou suspenso para ela, mas o tempo da escola continuou a caminhar e, ao aluno, é deixada a responsabilidade pelo ajuste a essa realidade.

\section{Situação 4}

Contexto: Bolívar (12 anos) tinha várias sequelas da doença e do tratamento. Precisava usar um colete de couro e ferros, que envolvia o pescoço, o tronco e os braços. Estava na $5^{\text {a }}$ série e, em sua primeira sessão, com a mãe presente, ele falou de suas dificuldades escolares. Carmem pediu para ver seu caderno.

Carmem: Tudo bem feitinho, Bolívar.

Bolívar: É, o que a professora não resolve, eu copio dos colegas.

Carmem nota que as lições do caderno estavam completas, sem erros importantes.

Carmem: Em qual matéria você está com dificuldades?

Bolívar: Português.

Carmem: E suas notas na escola? Tem alguma ruim?

Bolívar: Não, vou indo. 
Carmem tenta entender a dificuldade que o menino efetivamente apresenta.

Carmem: Vou fazer algumas perguntas pra você, só que você escreve a resposta. Qual o seu nome?

Ele escreve o nome inteiro na folha.

Carmem: 0 que você mais gosta?

Ele olha para a mãe, troca a caneta por um lápis. A mãe diz "gato". Ele tenta escrever, depois risca. Tenta escrever "o que eu mais gosto", mas também não consegue e sua mãe ajuda soletrando. Ela repete "gato". Na continuação da atividade, ele se esforça para escrever sempre com a ajuda da mãe. Aparenta nervosismo e muito constrangimento em mostrar que não sabe.

Ficou claro que o problema de Bolívar era não estar alfabetizado. Ele não tinha notas ruins e seu caderno era organizado, razoavelmente correto. Sua professora dava um apoio ocasional, mas ele basicamente copiava as tarefas e era avaliado pelas cópias feitas, apesar de não saber ler e escrever, como ficou confirmado nas sessões posteriores. Numa delas, Bolívar disse "Meu sonho é aprender a ler". E sua mãe falava da tristeza por não poder pagar um professor particular em virtude da pobreza da família, comentário esse que era feito também por outras mães ao longo da participação no programa.

As falas das crianças indicam que a escola não responde às suas dificuldades, mas algumas vezes o modo como se manifestam sugere que elas acabam atribuindo a si a responsabilidade pelo fracasso, como é o caso de Celso.

\section{Situação 5}

Contexto: Celso (10 anos) estava em tratamento há cerca de quatro anos. Matriculado na $4^{\text {a }}$ série, ele tinha frequentado a escola esporadicamente, por períodos de poucos meses. Conseguia ler frases simples, escrevia com alguma dificuldade e fazia pequenas operações de soma e subtração.

Carmem: Olá, Celso. Como vai?

Celso: Vou indo.
Carmem: Fiquei sabendo que seu tratamento terminou, é isso mesmo?

Celso: É sim, vou só fazer acompanhamento. (responde sorrindo muito)

Carmem: Então veio para se despedir?

Celso: Não, ainda vou fazer um montão de exames antes de ir para casa. E volto sempre para ver se o tumor não volta.

Carmem: E hoje, o que vamos fazer?

Celso escolheu uma atividade com o CDROM do Rei Leão. Na continuação da conversa com Carmem, ele se refere à escola, com tom de descontentamento.

Celso: É que não quero ir para escola, mas vou ter que voltar.

Carmem: Mas por que você não quer ir à escola?

Celso: Não sei, é muito chato. Fico lá sentado, olhando e desenhando. Os outros gozam de mim.

Carmem: Mas você aprende muita coisa também, não é?

Celso: Não sei nada, os outros sabem.

Carmem: 0 que você não sabe, aprende.

Celso: Então, passa uma lição pra mim.

As crianças recém-afastadas da escola mostram tristeza por perder sua rotina e a interrupção passa a ser tema de suas conversas. Já para aquelas que estão retornando à escola, como Celso, o medo e a insegurança desse retorno tornam-se fortemente presentes, produzindo uma tendência a evitar a ida às aulas. 0 mesmo ocorria com Cacá.

\section{Situação 6}

Contexto: Nesse dia, Cacá (10 anos), aluno da $5^{\text {a }}$ série, reapareceu no programa após um período de ausência. Estava indo à escola esporadicamente, pois as exigências do tratamento ainda impossibilitavam o comparecimento regular. Cacá mostra seu caderno para Carmem.

Carmem: Muito bem, que beleza! Você está frequentando a escola?

Cacá: Vou de vez em quando, mas como 
tenho que vir ao hospital e tenho muita ânsia, a professora disse que posso ficar em casa, sou muito esperto e quando voltar pego tudo rapidinho.

Carmem: E você sente falta?

Cacá: Não, nem quero saber mais disso. Eles que fiquem pra lá.

Vemos que Cacá conta com o consentimento da professora, que o autoriza a faltar às aulas. A complacência encobre a omissão da escola, que não oferece qualquer alternativa para ensiná-lo e não cogita de providências (que por certo envolvem outras instâncias) para o atendimento domiciliar a que o aluno tem direito. Por outro lado, como ocorre com a maioria dessas crianças, ele pode contar com a aprovação ao final do ano, sem ter aprendido. Seu desabafo "Eles que fiquem pra lá" parece incluir colegas e adultos, mostrando também o descontentamento com a convivência na escola. Essa insatisfação era expressa por todos os participantes do programa, por vezes com profundo ressentimento, como podemos observar no relato de Vânia.

\author{
Situação 7 \\ Contexto: Vânia (7anos), aluna da $1^{\text {a }}$ série, \\ veio pela primeira vez ao programa e pediu \\ para participar das atividades. \\ Carmem: Você vai à escola? \\ Vânia: Às vezes. \\ Carmem: E gosta? \\ Vânia: Eu gosto, mas nem sempre. \\ Carmem: Do que gosta? \\ Vânia: De lição, da professora. Não gosto \\ de ir ao banheiro. \\ Carmem: Como assim? \\ Vânia: É que me chamam de menino. \\ (Ela perdeu totalmente os cabelos por cau- \\ sa do tratamento) \\ Carmem: E o que acontece? \\ Vânia: Choro e vou embora.
}

Vânia diz gostar das lições, porém vai à escola "às vezes", e isso sugere uma experiência limitada quanto à aprendizagem alcançada. No entanto, o que se sobressai em sua fala é a questão da convivência com os pares, que inclui momentos de rejeição e de deboche (não deveria usar o banheiro das meninas, já que é "um menino"). 0 problema de Vânia é semelhante ao de vários outros participantes do programa como aqueles que também perdem o cabelo, por períodos variáveis, ou que precisam de recursos como Bolívar, cujo colete estranho causa perplexidade. Eles apresentam diversas marcas visíveis (dificuldade de locomoção; perda de movimento do braço; uso de prótese na perna; uso de cadeira de rodas ou muleta) que podem gerar nas pessoas afastamento ou por vezes reações e dizeres ofensivos.

Assim, antes aceita em maior ou menor grau pelo seu grupo, a criança retorna diferente à escola. Faz um tratamento que os colegas desconhecem, e seu organismo, agora enfraquecido, mostra sequelas que assumem uma dimensão acentuada pelo olhar do outro. As crianças estudadas parecem saber que sua imagem é de doente-doença. Trazem no semblante a tristeza não apenas pela condição orgânica, mas pelo estigma. Se a doença exigiu períodos de afastamento de esferas do meio social, é nos períodos de retomada de espaços de relações interpessoais, como o da escola, que o isolamento se torna mais presente. No encontro entre doentes e saudáveis, a segregação acaba sendo evidenciada.

As significações atribuídas à doença com risco de morte fazem com que as ações sociais, embora ofereçam alguns dos benefícios a que o indivíduo tem direito, guiem-se mais pelos malefícios que ele poderá causar à coletividade. Sua existência impõe um indesejável contato com o anormal e o imperfeito, além de trazer um ônus de ordem econômico-financeira (improdutividade e custos de tratamento), problemas esses que correspondem a alguns dos temas abordados por Foucault (2001) em sua importante discussão de sobre o nascimento da clínica.

\section{Considerações gerais}

Os apontamentos aqui feitos sobre as crianças com câncer mostram que sua vida confi- 
gura um cenário de marcante limitação. Há restrições relativas aos processos orgânicos gerados pela doença, mas muitas das perdas são produzidas pela cultura, que transforma o doente em sua doença e o vê em suas impossibilidades, ao invés de privilegiar suas potencialidades, como argumenta Vygotsky (1997).

De forma equivalente a outros setores da sociedade, a escola assume uma desistência antecipada, pois deixa de ensinar em função da doença que afeta o aluno. Com isso, o surgimento ou a acentuação de dificuldades tornase inevitável. Vimos que as crianças adoecidas, cada uma dentro de seu nível de elaboração, percebem isso ("minha professora não ensina"; "eu copio bastante, mas não entendo nada”). Por outro lado, ficam na ambi-guidade de relacionar suas dificuldades de aprendizagem tanto ao fato de não serem ensinadas como a uma incapacidade sua (o que se revela, por exemplo, pela falta de desejo de ir às aulas ou por afirmações como "eu não sei nada, os outros sabem”; “nem quero saber mais disso [da escola]").

Nesse cenário, entrelaçam-se vários problemas. A formação do educador para trabalhar em classe hospitalar ou atendimento domiciliar praticamente ainda não é oferecida e falta a conscientização da escola diante das necessidades das crianças hospitalizadas. Ademais, há pouco reconhecimento do setor da saúde quando o assunto é pedagogia hospitalar. Por isso, mostra-se urgente um trabalho colaborativo entre os ambientes de educação e saúde, que coexistem hoje sem uma integração, como alertam Caiado (2000) e Barros (2007). As políticas educacionais vêm estabelecendo diretrizes nesse sentido. Todavia, a articulação dos dois setores mostra-se mais complexa e desafiadora do que sugere o discurso da lei, além de o poder público não oferecer os recursos e mecanismos necessários para seu cumprimento.

0 cerceamento da continuidade dos estudos provoca intensa perda, pois as crianças são deslocadas da esfera que é central no desenvolvimento cultural dessa etapa, nos termos de Vygotsky (1995), ou da atividade principal desse período da infância, nos termos de Leontiev (1988). Em decorrência, elas são postas numa espécie de limbo dos espaços da vida da cultura.

0 sistema escolar tem a responsabilidade de conduzir programas no ambiente hospitalar, disponibilizar atendimento domiciliar conforme o momento do tratamento e criar formas diferenciadas para atender a esses alunos em seus retornos à escola. Cabe registrar que nenhuma das crianças estudadas usufruía desses direitos e lembrar que o próprio programa aqui abordado apresentava limitações de recursos físicos e materiais (por exemplo, quanto às instalações) e de tempo abrangido (uma vez por semana).

Estamos longe de uma configuração desejável de educação nessa área, mas a escola pode começar a acolher o aluno e, no processo, desenvolver compreensão e sensibilidade para saber atuar na alternância de interrupções e retomadas das atividades de estudo.

Para resumir, destacamos dos achados três indicações interligadas.

0 contexto escolar intensifica os obstáculos em virtude da desatenção, condescendência e exceção ao conceder a não obri-gatoriedade do estudo e da aprendizagem. 0 direito a aprender é tornado um direito a não aprender. Para famílias de baixo nível socio-econômico, esse é um prejuizo que se acrescenta ao sofrimento pela doença, visto que geralmente atribuem uma grande importância às atividades escolares, pela esperança de um futuro melhor para seus filhos. Dessa maneira, o peso social da doença se multiplica para a criança: o deslocamento da atividade principal da infância, a inferiorização pelo não saber, o sofrimento frente aos preconceitos e a precária condição de vida familiar com suas inúmeras consequências.

Precisamos reconhecer que a postura da escola e dos educadores é compreensível porque, diante de uma condição tão mobilizadora como o câncer, ao lado da desinformação, talvez se tenha a intenção de reduzir as demandas para uma criança cuja prioridade é sobre- 
viver. No entanto, essa criança deseja viver e é muito receptiva para aprender como os dados mostram. Assim sendo, a postura marcada pela piedade e insegurança não só leva ao desperdício de seu potencial e vitalidade como também lhe traz uma dor adicional, pois ela sente e expressa a exclusão e a inferioridade do lugar em que foi colocada.

É evidente a necessidade de adensar o significado desse atendimento educacional que, segundo Fontes (2005) e Matos (2006), precisa promover a elaboração do conhecimento sistematizado escolar, porém fundamentalmente oferecer uma experiência que minimize o sofrimento e os diversos problemas advindos do tratamento hospitalar. Concordamos com a afirmação, mas acrescentamos uma ressalva. Mesmo em casos de enfermidades graves como o câncer, o conteúdo escolar não deve ser secundarizado, pois esse conhecimento também contribui para a minimização do sofrimento e, mais, constitui uma fonte de vontade de viver. Isso porque, em nossa interpretação, querer fazer continhas, realizar exercícios de escrita, dominar a grafia manuscrita etc. são pequenos indícios de busca pela manutenção de vínculo com a vida e têm um valor de futuro projetado.

Essas três indicações podem ser reportadas a muitas das falas das crianças, que expressam a significação que atribuem ao aprender e à aprendizagem escolar. Por exemplo, Marta, de 9 anos, entristecida, conversa com a coordenadora sobre o tratamento e a impossibilidade de frequentar as aulas. Em seguida, já com bom humor, pede: "E aí, tia, rola uma lição".

\section{Apontamentos finais}

São conhecidos os entraves da estrutura e da organização escolar que repercutem no processo ensino-aprendizagem e as precárias condições que os professores enfrentam em seu trabalho. Dizse que a escola não atende efetivamente sequer a seus alunos comuns, menos ainda aos que têm necessidades peculiares como o grupo focalizado neste trabalho. Essa constatação procede. Contudo, não se pode pactuar com a protelação das soluções e com a continuação da mescla de negligência e piedade que conduz à ilusória facilitação oferecida ao aluno que está doente. Ele não é ensinado e não se espera que aprenda. Tudo se resolve com avaliações fictícias, aceitação da mera cópia e promoção sem exigências.

Diversas instituições fazem perdurar a realidade descrita. Naturalmente o problema não é apenas da escola, visto que, como parte da rede de instâncias de representações e práticas sociais, ela assimila e reflete concepções, imagens e formas de ação. No entanto, como argumentamos, há nela uma especificidade que a coloca numa posição especial e central para qualquer criança em nossa cultura. Para a criança doente, sua atuação despreparada provoca efeitos muito prejudiciais à vida. Contudo, apesar ou por conta mesmo de suas funções contraditórias (que dão margem a transformações), a escola pode produzir efeitos em direções desejáveis e, com isso, assumir um papel decisivo na busca de mudanças do atendimento educacional a que tem direito essa pequena, mas não menos importante, parcela da população infantil. 


\section{Referências bibliográficas}

BARROS, A. S. S. Contribuições da educação profissional em saúde à formação para o trabalho em classes hospitalares. Cadernos Cedes, Campinas, v. 27, n. 73, p. 257-278, set./dez. 2007.

BRASIL. Ministério da Educação. Secretaria de Educação Especial. Política Nacional de Educação Especial. Brasília: Secretaria de Educação Especial, 1994. MEC, $\overline{2001 .}$

. Diretrizes Nacionais para Educação Especial na Educação Básica. Conselho Nacional de educação. Brasília:

Classe hospitalar e atendimento pedagógico domiciliar: estratégias e orientações. Secretaria de Educação Especial. Brasília: MEC; SEESP, 2002. 35p.

CAIADO, K. R. M. 0 trabalho pedagógico no ambiente hospitalar. In: ENDIPE, Ensinar e aprender: sujeitos, saberes, espaços e tempos. Anais... Rio de Janeiro: 10, 2000. p. 274-277.

FONSECA, E. S. A situação brasileira do atendimento pedagógico-educacional hospitalar. Educação e Pesquisa, São Paulo, v. 25, n. 1, jun. 1999, p. 117-129.

FONTES, R. S. A escuta pedagógica à criança hospitalizada: discutindo o papel da educação no hospital. Revista Brasileira de Educação, São Paulo, n. 29, 2005, p. 119-138.

FOUCAULT, M. 0 nascimento da clínica. 5. ed. Rio de Janeiro: Forense Universitária, 2001.

INCA: Instituto Nacional do Câncer. Estimativas da incidência e mortalidade por câncer no Brasil, 2000. Disponível em <http:/ /www.inca.gov.br/situaca0>. Acesso em 25 jan. 2007.

LEONTIEV, A N. Actividad, conciencia e personalidad. Havana: Pueblo y Educación, 1983. Disponível em <http:// www.dominiopublico.gov.br/download/texto/ma000004.pdf>. Acesso em: 10 jan. 2007.

Uma contribuição à teoria do desenvolvimento da psique infantil. In: VYGOTSKY, L. S. Linguagem, desenvolvimento e aprendizagem. São Paulo: Edusp, 1988.

LÜDKE, M.; ANDRÉ, M. E. D. A. Pesquisa em educação: abordagens qualitativas. São Paulo: EPU, 1986.

MATOS, E. L. M. Pedagogia hospitalar: a humanização integrando educação e saúde. Rio de Janeiro: Vozes, 2006.

MINAYO, M. C. de S. (Org.) Pesquisa social: teoria, método e criatividade. 2. ed. Rio de Janeiro: Vozes, 1994.

NIGRO, M. Hospitalização: o impacto na criança, no adolescente e no psicólogo hospitalar. São Paulo: Casa do Psicólogo, 2004.

SONTAG, S. A doença como metáfora. Rio de Janeiro: Graal, 1984.

VYGOTSKY, L. S. Problemas del desarrollo de la psique. Obras Escogidas. v. III. Madri: Visor, 1995.

Fundamentos de defectología. Obras escogidas. v. V. Madri: Visor, 1997.

Recebido em 04.11.08

Aprovado em 10.08 .09

Carmem Lúcia Artioli Rolim, doutora em Educação pela UNIMEP, é docente da Universidade Federal do Tocantins. Entre 2003 e 2008, desenvolveu na UNISO projeto de atendimento pedagógico para crianças hospitalizadas.

Maria Cecília Rafael de Góes, mestre e doutora em Psicologia pela USP e livre-docente pela UNICAMP, é docente do Programa de Pós-Graduação em Educação da UNIMEP. 